\title{
A Study on Damage and Crack Propagation in Ceramics under the Static and Cyclic Conditions
}

\author{
Tatsuyuki NEZU \\ Department of Chemical and Materials Engineering National Chin-Yi University of Technology \\ No.57,Sec.2, Zhong shanRd., Taiping Dist.,Taichung 41170, Taiwan, ROC \\ E-mail: kelvinyu@ncut.edu.tw
}

Keywords: Ceramics, Crack, Indented, Stress Distribution ,Finite Element Method

Abstract. In this study, the three-dimensional stress distributions in the area surrounding indentation pattern for three different materials, $\mathrm{Al}_{2} \mathrm{O}_{3}, \mathrm{Si}_{3} \mathrm{~N}_{4}$ and $\mathrm{SiC}$ were analyzed by FEM. Those theoretical results were also compared with the experimental ones by Rockwell hardness test. The effect of loading stress on the plastic deformation in specimens, surface was investigated on the assumption of shear strain energy theory by Huber-mises when the materials were indented. The distributions of nomal stress, shear stress, and mises stress were analysed with variations of loading conditions. It is clear that the analytical results for the stress distributions, the crack length and its density of probability are in good agreement with the experimental results.

\section{Introduction}

According to the above situation, in this study, the three-dimensional stress distributions of indentation pattern for three different materials, $\mathrm{Al}_{2} \mathrm{O}_{3}, \mathrm{Si}_{3} \mathrm{~N}_{4}, \mathrm{SiC}$ were analyzed. The effect of loading stress on the plastic deformation on test surface was investigated with variations of loading conditions by FEM. According to the indentation pattern, under the assumption of shear strain energy theory by Huber-mises, the beginning of the plastic deformation and the distributions of loading stress were analyzed. The aim of the paper was to propose the present analysis ${ }^{[4]}$ for the stress distributions, the crack length and its density of probability.

\section{Experimental}

Mechanical Properties Microstructures of Materials. $\mathrm{Al}_{2} \mathrm{O}_{3}$ used in the experiment was from (A-473); $\mathrm{Si}_{3} \mathrm{~N}_{4}(\mathrm{SN}-220)$, $\mathrm{SiC}(\mathrm{SC}-211)$. The mechanical properties of materials are shown in Table 1. Especially, the stress intensity factor $\mathrm{K}_{\mathrm{IC}}$ was calculated by IF method. IM method refers to the hemicycle or semi-elliptic vertical crack near the indentation during the Vickers indentation test on the surface of brittle ceramics. The value of the crack was evaluated using $\mathrm{K}_{\mathrm{IC}}$. The samples were 10 $\mathrm{mm} \times 20 \mathrm{~mm} \times 60 \mathrm{~mm}$. After the samples were ground, the indentation zone and crack-tip were observed by optical microscopy. After corrosion treatment, namely, $\mathrm{Al}_{2} \mathrm{O}_{3}$ with $30 \% \mathrm{NaOH}$ solution, $\mathrm{Si}_{3} \mathrm{~N}_{4}$ and $\mathrm{SiC}$ with $60 \% \mathrm{HNO}_{3}$ solution respectively at $70^{\circ} \mathrm{C}$ for $5 \mathrm{~min}$, the evaporation of treated samples was observed by Scanning Electron Microscopy (SEM).

\begin{tabular}{|c|c|c|c|}
\hline Material & $\mathrm{Al}_{3}$ & $\mathrm{SinN}_{4}$ & $\mathrm{SiC}$ \\
\hline Percentage of & & 91 & 98 \\
\hline $\begin{array}{l}\text { Mass \% } \\
\text { Rockwell }\end{array}$ & HRA 87 & HRA 91 & HRA 94 \\
\hline $\begin{array}{l}\text { Hardness } \\
\text { Bending }\end{array}$ & & & \\
\hline $\begin{array}{l}\text { Strength MPa } \\
\text { Compressive }\end{array}$ & 314 & 588 & 539 \\
\hline $\begin{array}{l}\text { Compressive } \\
\text { Strength MPa }\end{array}$ & 2305 & 3900 & 5500 \\
\hline $\begin{array}{l}\text { Young's } \\
\text { Modulus GPa }\end{array}$ & 265 & 294 & 432 \\
\hline Poisson"s Ratio & 0.23 & 0.28 & 0.16 \\
\hline $\mathrm{MPa}^{\mathrm{K} x} \cdot \mathrm{m}^{1 / 2}$ & 4.0 & 5.7 & 5.6 \\
\hline
\end{tabular}

Table 1. Mechanical Properties of materials

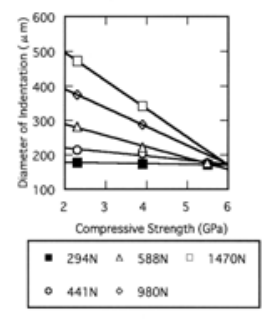

Fig 1a Compressive vs. Diameter of Indentationvs. Diameter of Indentation

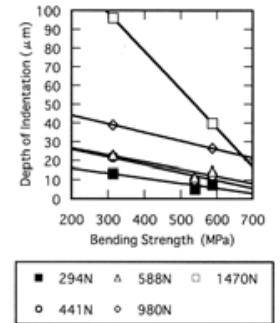

Fig 2a Bending Strength vs.Depth of Indentation 


\section{Results}

Evaluation of indentation damage. The Rockwell indenter was forced on test surface with an apex angel $120^{\circ}$. Usually, the elastic deformation firstly took place, then turned into the plastic deformation as loading up. However, on the very brittle surface of the ceramics, if loading up more, the crack extended around the radius between elastic and plastic zone. The beginning of radial rack and the indentation extending down has been known[5,6]. The average of the maximum diameter and orthogonal diameter was considered as the representative one. The relationships of diameter, compressive strength and Young's Modulus are shown in Fig. 1a and Fig. 1b. The indentation diameters descend linearly in order of $\mathrm{Al}_{2} \mathrm{O}_{3} 、 \mathrm{Si}_{3} \mathrm{~N}_{4}$ and $\mathrm{SiC}$ and those compressive strength and Young's Modulus are constants respectively. When the samples in the experiment were loaded from $294 \mathrm{~N}$ to $1470 \mathrm{~N}$, the linear slope gradually trends bigger. The porosity, crystal morphology, grain, matrix and relative mechanical properties were close related one another. The bending strength vs. depth of indentation is shown in Fig.2a and Fig. 2b. As the increasing of the bending strength and $\mathrm{K}_{\mathrm{IC}}$, the depth of indentation descended gradually in order of $\mathrm{Al}_{2} \mathrm{O}_{3}, \mathrm{Si}_{3} \mathrm{~N} 4$ and $\mathrm{SiC}$ as loading from $294 \mathrm{~N}$ to $1470 \mathrm{~N}$.

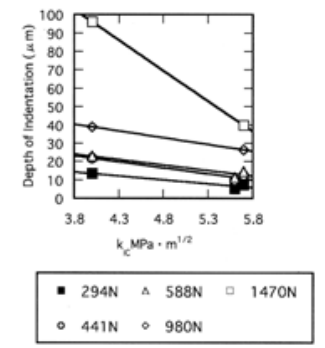

Fig $2 \mathbf{b} \mathrm{K}_{\mathrm{IC}} \mathrm{MPa} \cdot \mathrm{m}^{1 / 2}$

Depth of Indentation

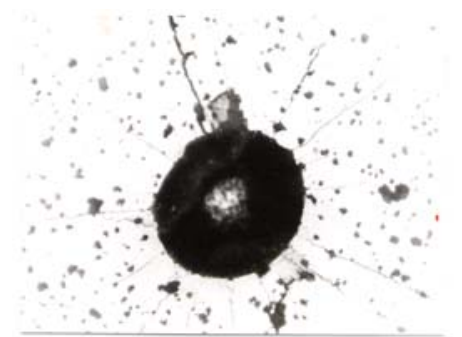

Fig 3a. Typical residual crack patterns on indented surface of ceramics $\left(\times 100, \mathrm{Al}_{2} \mathrm{0}_{3}, 294 \mathrm{~N}\right)$

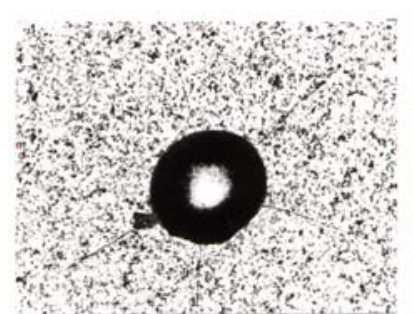

Fig 3b. Typical residual crack patterns on indented surface of ceramics $\left(\times 100, \mathrm{Si}_{3} \mathrm{O}_{4}, 294 \mathrm{~N}\right)$

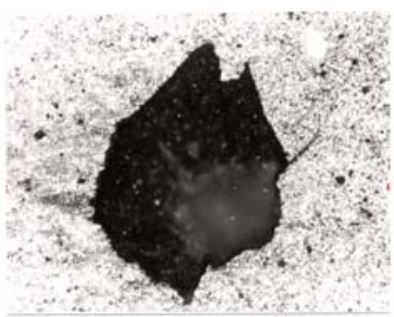

Fig 3c. Typical residual crack patterns on indented surface of ceramics $(\times 100, \mathrm{SiC}, 294 \mathrm{~N})$

Effect of the compressive strength on the deformation.Due to the indenter test, an indentation occurred on the test surface, near which was the crack. The typical residual crack patterns on indented surfaces of ceramics are shown in Fig. 3. It is concluded that, when loading up to $294 \mathrm{~N}$, the indentation is mainly the crown, extending from the center on radial crack. Especially, when using $\mathrm{SiC}$ materials, the indentation extended along the test surface, and turned bigger in turn as loading up. The radical crack extended indented instead of linear. The indented crack spread to the pores. As a stress raiser, the pores caused partial damage, forming chapping. The change of extending direction ceased the chapping. However, as shown in Fig. 4, under the condition of $p=294 \mathrm{~N}$, the depth indentation of $\mathrm{Al}_{2} \mathrm{O}_{3}, \mathrm{Si}_{3} \mathrm{~N}_{4}$ and $\mathrm{SiC}$ are $140 \mu \mathrm{m}, 90 \mu \mathrm{m}$, and $120 \mu \mathrm{m}$ respectively. There is a little error between the calculating ones and testing ones, which resulted from the actual measuring $[7,8,9,10]$.
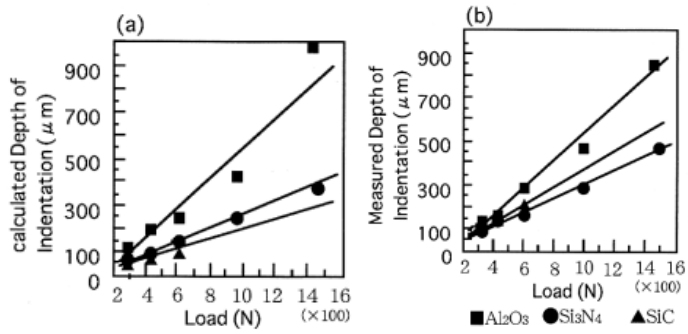

Fig 4. Relation between depth of indentation andcompressive load:(a). Load vs calculatd depth of Indentation (b). Load vs measured depth of Indentation

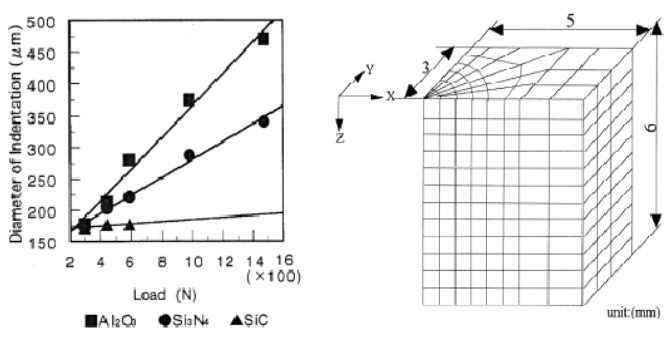

Fig 5. Load vs. Diameter of Indentation
Fig 6. Mesh patterns of FEM model 

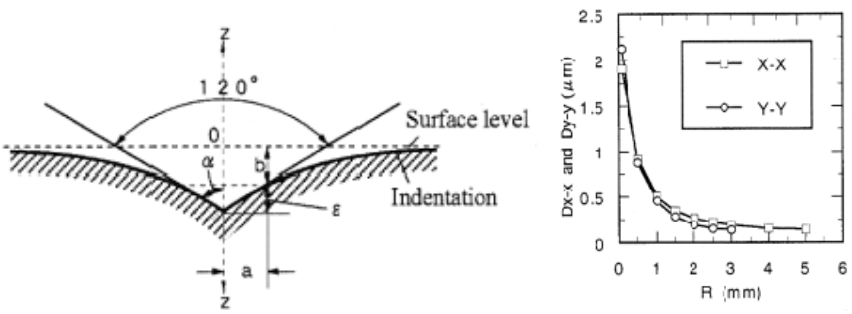

Fig 7. Pressed by diamod conical indenter Fig 8a. $D_{\mathrm{X}-\mathrm{X}}$ and $\mathrm{D}_{\mathrm{Y}-\mathrm{Y}}$ displacement displacement

\section{Analyzing the data by FEM}

\section{Damage behavior simulation by FEM}

Analyzing the damage behaviors, Finite Elements Method was adopted using Marc volume program. The stress distribution, shear stress and mises stress were analyzed by workstation. The actual deformation was elastic originally, then turned into one in the equilibrant state as the motion of the indenter. Limited by the elements of calculating time and content, the nodes changed from 754 to 576 . These elements were composed of pentahedron of 72 elements and hexahedron 504 elements. Degrees of Freedom of total model didn't turn comparing with $\mathrm{X}$-axis and Y-axis, only parallel moving. Due to the body symmetry one-quarter of the indented microarea was used for the calculation, here, the boundary condition was limited to move in the direction of Z-axis. The aim was to investigate the inner damage of indentation pattern for three materials, considering the contacted section and the immobility of fixed surface as the boundary condition. Mesh patterns of FEM model under the loading of $294 \mathrm{~N}$, are shown in Fig. 6 . The loading conditions were estimated by analyzing the chapping caused near the indentation region by FEM. It is inapplicable for the given model to carry out the calculating by the method. Therefore, the indentation was proximate taper, whose radius can be decided by the average of thirty samples. The depth of indentation can be obtained by the following Formula (1).

Depth of indentation $\mathrm{h}(\mathrm{mm})=(100$-regidity $) \times 0.002 \quad(1)$

The values are shown in Fig. 4. In this case, the stress distribution, shear stress and mises stress were calculated respectively.Moreover, the stress distributions are shown in Fig. 9a and Fig. 9b. For the values of $\mathrm{X}$-axis and $\mathrm{Y}$-axis, the stress distributions along the radius near the center of $\mathrm{Y}$-axis are bigger than that of $\mathrm{X}$-axis, and there is little difference near the boundary site. While, for the $\mathrm{D}_{\mathrm{x}-\mathrm{y}}$ and $\mathrm{D}_{\mathrm{y}-\mathrm{x}}$, the difference between $\mathrm{X}$-axis and $\mathrm{Y}$-axis is little, almost keeps the same near the boundary site.

The crack-tip stresses are shown in Fig. 10a Fig. 10b, respectively. For the $\mathrm{D}_{\mathrm{x}-\mathrm{x}}$ and $\mathrm{D}_{\mathrm{y}-\mathrm{y}}$, there is little difference along the radius. In the direction of cross section, its crack-tip stress in the center of circle varies inversely with the boundary length, and goes to zero away from the center along the radius, about zero. In the direction of $\mathrm{X}_{-\mathrm{zx}}$ and $\mathrm{Y}_{-\mathrm{yz}}$, the crack-tip stress has no relationship with $\mathrm{X}$-axis and $\mathrm{Y}$-axis, keeping the same, and in the great extent influences the creation of the crack.

The mises stress is shown in Fig. 11. The combined stress of compressive stress and crack-tip stress can be seen in Fig. 11. The mises stress has no relationship with X-axis and Y-axis, keeping the same, moreover there is a little difference along the radius, which can be used as the norm judging the creation of the crack.

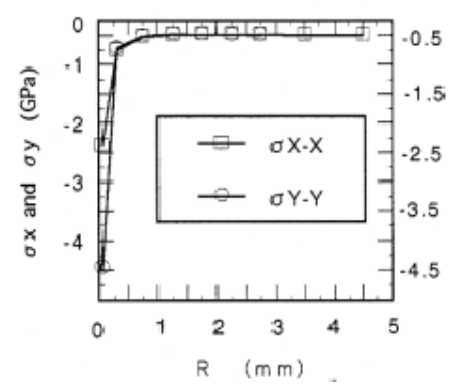

Fig 9a. $\sigma \mathrm{X}-\mathrm{X}$ and $\sigma \mathrm{Y}-\mathrm{Y}$ normal

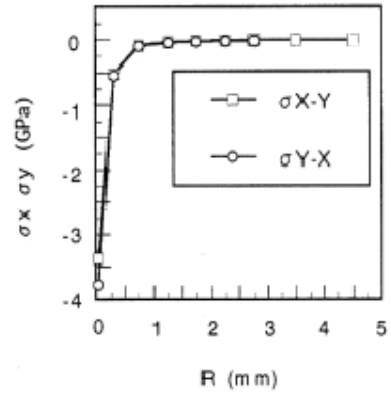

Fig 9b. $\sigma \mathrm{X}-\mathrm{Y}$ and $\sigma \mathrm{Y}-\mathrm{X}$ normal

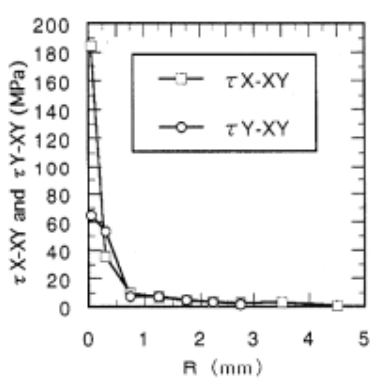

Fig 10a. $\mathrm{X}_{-\mathrm{XY}}$ and $\mathrm{Y}_{-\mathrm{XY}}$ shear distribution 


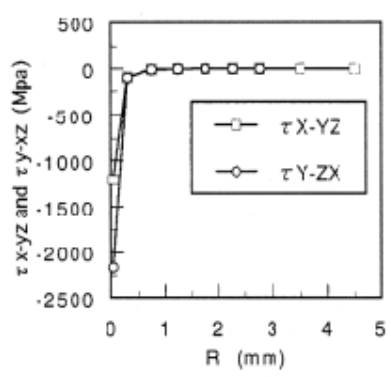

Fig 10b. $\tau_{\mathrm{X}-\mathrm{YZ}}$ and $\tau_{\mathrm{Y}-\mathrm{XZ}}$ shear

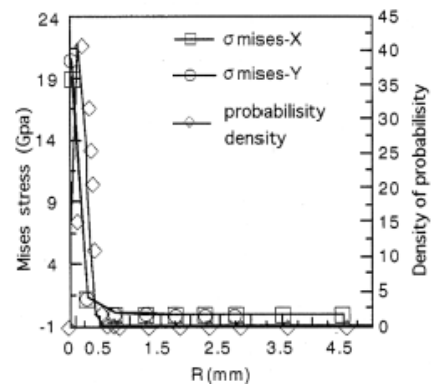

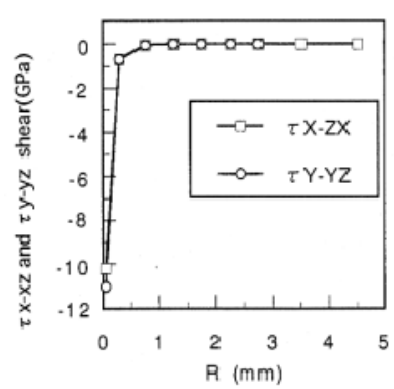

Fig 10c. $\tau_{\mathrm{X}-\mathrm{XZ}}$ and $\tau_{\mathrm{Y}-\mathrm{YZ}}$ shear

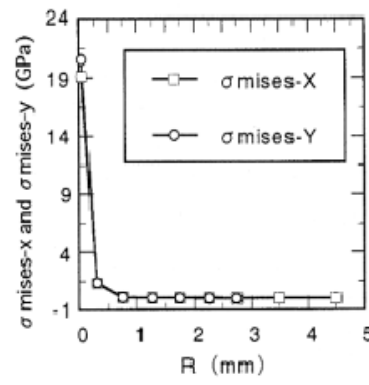

Fig 11. $\mathrm{X}$ and $\mathrm{Y}$ mises stress

Fig 12. Mises stress vs. probabilisity density five different conditions

\section{Conclusions}

The radial crack extended the indented shape. When spreading to the pores and the grain bound was damaged, thus the crack began to extend. Moreover, the crack ceased in the pore. The pore served as the place of concentrated stress, the crack occurred for the out lower stress resulted in the part damage. Therefore, the indented crack on the test surface, stopped because of the pores and the extending direction of crack changed.

The depth of indentation by Rockwell indenter test corresponds with the stress distribution by FEM. It is concluded that when $\mathrm{Al}_{2} \mathrm{O}_{3}$ crack occurred and if the crack spread easily depended on the values of mises stress. When the loading was 294N, for the stress and stress-tip distributions, shear stress and mises stress of $\mathrm{Al}_{2} \mathrm{O}_{3}$ materials, the $\mathrm{Y}$ deformation was bigger than that of $\mathrm{X}$. Thus, it is apt to bring and spread the radial crack in the direction of $\mathrm{X}$.

The crack occurred if the compressive strength was bigger than the bending strength. The density of probability of higher stress was higher than that of the lower. The above conclusions can be obtained from Fig. 12. Thus, the crack distributions can be evaluated by mises stress distributions.

\section{References}

[1] Hiroshige suzuki, takayoshi iseki "Ceramic Strength and Fracture of Materials" Kyouritusyubann Printed in Japan, (1992).

[2] Hamada seiiti, teramae tetuo, godai gigou, Journal of Japan Society of Mechanical Engineers A-60, 456, (1994).

[3] Hiroyuki kagawa, masahiro itikawa, tooru takamatu, Journal of Japan Society of Mechanical Engineers, A-58, 546(1990).

[4] Tenki yuu, kikuo nedu, J. Ceram. Soc. Japan, 104, 121-125, (1996).

[5] Hiromasa ishikawa, hiroshi ishii, takeru utida, Journal of Japan Society of Mechanical Engineers, A-56, 532, (1900).

[6] Hamilton, G. M. and Goodman, L. E.,Trans. ASME, Appl. Mech., 33 , 371-377(1966).

[7] Frank, F. C. and Lawn, B. R., Proc. R. Soc., A, 229, 291-267(1967).

[8] Irwin, G. R. Proc. 9th Int. Congr. Appl. Mech., 8, 245-251 (1957). 
[9] Honshin nishitani, hiroshi noguti, Journal of Japan Society of Mechanical Engineers, A-52, 477, (1986).

[10] Varias, A. G. and Shin, C.F., J. Mech. Phys. Solids, 415, 835-841(1993).

[11] Kenzirou komai, kouzi minozima, masaki ozima, Journal of Japan Society of Mechanical Engineers, A-54, 500, (1988).

[12] Tetushi tanaka, wataru huzisaki, honshin nishitani, takahiro teranishi, Journal of Japan Society of Mechanical Engineers, A-60, 596,(1994).

[13] Wataru huzisaki, honshin nishitani, tetushi tanaka, takahiro teranishi, Journal of Japan Society of Mechanical Engineers, A-60, 575,(1994).

[14] Warren, R., Acta Met., 26, 1759. (1978)

[15] Osamu sano, Journal of the Society of Materials Science,Japan, 37, 152,(1988).

[16] Johnson, K. L., O’Connor, J. J. and Woodward, A. C., Proc. R. Sov., London, A, 334, 95-101(1973).

[17] Akimune, J. Am, Cearm, Soc., 98, 25-29(1990).

[18] Honshin nishitani, norio kawakoishi, Journal of Japan Society of Mechanical Engineers, A-50, 450, (1984).

[19] Nose, T. and Fujii, T., J, Am, Ceram, Soc., 71, 328-334(1988). 